\title{
Characterization of the peripheral thyroid system of gilthead seabream acclimated to different ambient salinities
}

\author{
I. Ruiz-Jarabo ${ }^{\text {a,c,* }}$, P.H.M. Klaren ${ }^{\text {b }}$, B. Louro ${ }^{\text {c }}$, J.A. Martos-Sitcha ${ }^{\text {a,d,1 }}$, P.I.S. Pinto ${ }^{\text {c }}$, L. Vargas-Chacoff ${ }^{\text {e }}$, G. Flik ${ }^{\text {b }}$, \\ G. Martínez-Rodríguez ${ }^{\mathrm{d}}$, D.M. Power ${ }^{\mathrm{c}}$, J.M. Mancera ${ }^{\mathrm{a}}$, F.J. Arjona ${ }^{\mathrm{a}, \mathrm{b}, 2}$ \\ a Departamento de Biología, Facultad de Ciencias del Mar y Ambientales, Universidad de Cádiz, Av. República Saharaui s/n, E11519 Puerto Real, Cádiz, Spain

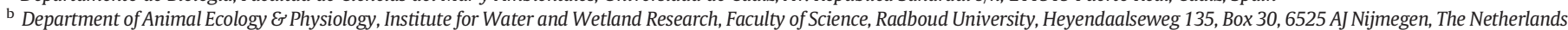 \\ c Comparative Endocrinology and Integrative Biology Group, Centre of Marine Sciences (CCMAR), Universidade do Algarve, Campus de Gambelas, 8005-139 Faro, Portugal \\ d Instituto de Ciencias Marinas de Andalucía (ICMAN-CSIC), Spanish National Research Council, Av. República Saharaui, 2, E11519 Puerto Real, Cádiz, Spain \\ e Instituto de Ciencias Marinas y Limnológicas, Facultad de Ciencias, Universidad Austral de Chile, Casilla 567, Valdivia, Chile
}

\section{A R T I C L E I N F O}

\section{Article history:}

Received 7 June 2016

Received in revised form 2 August 2016

Accepted 16 August 2016

Available online 21 August 2016

\section{Keywords:}

Deiodinases

Osmoregulation

Outer ring deiodination

Sparus aurata

Thyroid hormones

\begin{abstract}
A B S T R A C T
Thyroid hormones are involved in many developmental and physiological processes, including osmoregulation. The regulation of the thyroid system by environmental salinity in the euryhaline gilthead seabream (Sparus aurata) is still poorly characterized. To this end seabreams were exposed to four different environmental salinities ( $5,15,40$ and $55 \mathrm{ppt}$ ) for 14 days, and plasma free thyroid hormones (fT3, fT4), outer ring deiodination and $\mathrm{Na}^{+} / \mathrm{K}^{+}$-ATPase activities in gills and kidney, as well as other osmoregulatory and metabolic parameters were measured. Low salinity conditions (5 ppt) elicited a significant increase in fT3 (29\%) and fT4 (184\%) plasma concentrations compared to control animals (acclimated to $40 \mathrm{ppt}$, natural salinity conditions in the Bay of Cádiz, Spain), while the amount of pituitary thyroid stimulating hormone subunit $\beta$ (tshb) transcript abundance remained unchanged. In addition, plasma fT4 levels were positively correlated to renal and branchial deiodinase type 2 (dio2) mRNA expression. Gill and kidney T4-outer ring deiodination activities correlated positively with dio2 mRNA expression and the highest values were observed in fish acclimated to low salinities (5 and $15 \mathrm{ppt}$ ). The high salinity (55 ppt) exposure caused a significant increase in tshb expression (65\%), but deiodinase gene expression (dio1 and dio2) and activity did not change and were similar to controls (40 ppt). In conclusion, acclimation to different salinities led to changes in the peripheral regulation of thyroid hormone metabolism in seabream. Therefore, thyroid hormones are involved in the regulation of ion transport and osmoregulatory physiology in this species. The conclusions derived from this study may also allow aquaculturists to modulate thyroid metabolism in seabream by adjusting culture salinity.
\end{abstract}

(c) 2016 Elsevier Inc. All rights reserved.

\section{Introduction}

Thyroid hormones (THs) are truly pleiotropic in fish, affecting metabolism, reproduction, growth and osmoregulation, relevant physiological processes for aquaculture (Blanton and Specker, 2007). Thus, understanding how this system is regulated by the environment in cultured species, is key for the optimization of their culture. In the aquaculture ponds of the South of Spain, where culture of gilthead

\footnotetext{
* Corresponding author at: Departamento de Biología, Facultad de Ciencias del Mar y Ambientales, Universidad de Cádiz, Av. República Saharaui s/n, E11519 Puerto Real, Cádiz, Spain.

E-mail address: ignacio.ruizjarabo@uca.es (I. Ruiz-Jarabo).

1 Current address: Nutrigenomics and Fish Growth Endocrinology Group, Institute of Aquaculture Torre de la Sal, Consejo Superior de Investigaciones Científicas (IATS-CSIC), Ribera de Cabanes, E-12,595 Castellón, Spain.

2 Current address: Department of Physiology, Radboud Institute for Molecular Life Sciences, Radboud university medical center, Nijmegen, The Netherlands.
}

seabream (Sparus aurata) is carried out, salinity is highly variable and may well influence the thyroid system. In general, the fish thyroid system responds to stimuli by regulating the release of thyroid stimulating hormone (Tsh) that in turn stimulates the thyroid follicle to secrete thyroxine (T4) into the blood stream (Eales and Brown, 1993). Within the plethora of stimuli regulating the release of Tsh in fish, different salinity concentrations are postulated (Leatherland and Farbridge, 1992). Pituitary thyroid stimulating hormone subunit $\beta(t s h b)$ gene expression is under negative feedback control by plasma (free) thyroid hormones (Cohn et al., 2010; Manchado et al., 2008).

The pro-hormone T4 is deiodinated into bioactive triiodothyronine (T3) in the peripheral tissues (Bernier et al., 2009; Klaren et al., 2008). The regulation of deiodination in peripheral tissues is therefore a determining factor for the physiological effects of thyroid hormones.

Two iodothyronine deiodinases (Dio1 and Dio2) have outer ring deiodination (ORD) activities and in peripheral organs such as the gills and the kidney produce T3 from T4 that are directly involved in ion 
transport and osmoregulation (Arjona et al., 2008). The inactivation pathways of THs are catalysed also by Dio1 and by a third iodothyronine deiodinase, Dio3. Both Dio1 and Dio2 ORD activities have distinct substrate and co-substrate preferences (Klaren et al., 2012; Orozco et al., 2000). Reverse T3 (rT3) is usually the preferred substrate for Dio1 in mammals (Orozco et al., 1997) while T4 is the preferred substrate of Dio2 (Garcia-G et al., 2004).

One consequence of increased TH activity is the stimulation of the basal metabolic rate, which seems to result, at least in part, in increased oxygen consumption and ATP hydrolysis. Several studies have reported species-specific changes in plasma TH levels, ORD activity (Arjona et al., 2008) or deiodinase gene expression (Lorgen et al., 2015) when fish are submitted to an osmotic challenge. Osmotic acclimation in fish is also associated with variations in plasma THs and in gilthead seabream plasma free T4 and gill ORD activity respond to a change in environmental salinity from 35 ppt to 1 ppt (Klaren et al., 2007).

Other authors have studied the thyroid system in S. aurata in hypo-saline conditions (Klaren et al., 2007; Power et al., 2001). To our knowledge, there are no previous studies characterizing the effects of acclimation to iso- or hypersaline conditions on the thyroid system in this species. We therefore set out to compare the effects of environmental hypo- and hyper-salinity on the thyroid system of the euryhaline gilthead seabream, an important aquaculture species.

\section{Materials and methods}

\subsection{Animal maintenance prior to experimentation}

Immature juvenile gilthead seabream juveniles $(N=32 ; 200 \pm 44 \mathrm{~g}$ body mass, mean $\pm \mathrm{SD}$ ) were provided by Servicios Centrales de Investigación en Cultivos Marinos (SCI-CM, CASEM, University of Cádiz, Spain; Operational Code REGA ES11028000312), and maintained in the fish husbandry facility of the Faculty of Marine and Environmental Sciences (Puerto Real, Cadiz, Spain). Fish were acclimated for 35 days in 400-L tanks to seawater (40 ppt, natural salinity condition in the Bay of Cadiz, Spain) in a flow-through system under natural photoperiod (month of May in Cadiz, $14 \mathrm{~h}$ light:10 h dark) and temperature (environmental temperature of approximately $19.5^{\circ} \mathrm{C}$ ). Fish were fed commercial pellets ( $1 \%$ body mass) once a day (9:00) (Dibaq-Diproteg, Segovia, Spain). The experimental procedures complied with the guidelines of the University of Cadiz (Spain) and the European Union $(86 / 609 / \mathrm{EU})$ for the use of animals in research.

\subsection{Acclimation to different environmental salinities}

Fish were lightly anaesthetized in $0.05 \%(v / v) 2$-phenoxyethanol, netted and randomly allocated to 400-L cubic tanks with different salinities (5, 15, 40 and 55 ppt with 140,364, 1090 and $1546 \mathrm{mOsm} \mathrm{kg}^{-1}$ osmolality, respectively) ( $N=8$ per group). During transfer to the experimental tanks, the mass and length of the animals were recorded. Experimental salinities were achieved by mixing full-strength seawater with dechlorinated tap water (Puerto Real, Spain) or by mixing seawater with natural marine salt (Salina La Tapa, Puerto de Santa María, Cádiz, Spain). Each tank had a water recirculation system, which consisted of an external filter (Hydor Prime 30, Sacramento, CA, USA) to ensure optimal water conditions. Water conditions during experimentation were: temperature, ranging between 19.1 and $19.8^{\circ} \mathrm{C}$; $5,15,40$ and 55 ppt salinity (variations $<1 \mathrm{ppt}$ for each tank); $\mathrm{pH}$, ranging between 7.82 and 7.88; dissolved oxygen, $>5 \mathrm{mg} \mathrm{O}_{2} \mathrm{~L}^{-1}$; nitrites, between 0.05 and $1.69 \mathrm{mg} \mathrm{L}^{-1}$; nitrates, between 4.13 and $36.41 \mathrm{mg} \mathrm{L}^{-1}$; and ammonium, $0.0-0.2 \mathrm{mg} \mathrm{L}^{-1}$. These parameters were checked daily and did not vary significantly for the duration of the experiment. $20 \%$ of the water in circuits was replaced every other day. Fish were maintained in these conditions for 14 days and were fasted for $24 \mathrm{~h}$ before sampling. No mortality was observed during the acclimation period.

\subsection{Sampling}

Fish were netted, anaesthetized in $0.1 \%(v / v)$ 2-phenoxyethanol, weighed and sampled. Blood was collected with ammoniumheparinized syringes from the caudal vessels and placed into heparinized tubes. Plasma was separated from cells by centrifugation of whole blood ( $3 \mathrm{~min}, 10,000 \times \mathrm{g}, 4^{\circ} \mathrm{C}$ ). Fish were then euthanized by spinal transection and the pituitary gland was collected from each fish. The first gill arch on the left side of fish was excised. Adherent blood was removed by blotting with absorbent paper and a smaller subsample consisting of a few branchial filaments was collected using fine-point scissors. A small portion of the caudal part of the kidney was also collected. Gill filaments and kidney were placed in $100 \mu \mathrm{L}$ of ice-cold sucrose-EDTA-imidazole (SEI) buffer $(150 \mathrm{mM}$ sucrose, $10 \mathrm{mM}$ EDTA, $50 \mathrm{mM}$ imidazole, $\mathrm{pH}$ 7.3) for the analysis of $\mathrm{Na}^{+} / \mathrm{K}^{+}$-ATPase activity. The remaining gill tissue and kidney were snap frozen in liquid nitrogen and stored at $-80^{\circ} \mathrm{C}$ until measurement of outer ring deiodination activities or mRNA extraction. Liver was also collected and weighed to determine the hepatosomatic index (HSI).

\subsection{Water chemistry}

Water samples were filtered $(0.22 \mu \mathrm{m}$ pore size $)$ prior to analysis. $\mathrm{Na}^{+}, \mathrm{K}^{+}$and $\mathrm{Mg}^{2+}$ levels were measured using a flame atomic absorption spectrophotometer (UNICAM 939, Servicios Centrales, University of Cadiz). $\mathrm{Cl}^{-}$and $\mathrm{Ca}^{2+}$ levels were measured with commercially available kits following the manufacturers protocol (Spinreact S.A, Sant Esteve d'en Bas, Girona, Spain). Osmolality was measured using a vapour pressure osmometer (Fiske One-Ten osmometer, Fiske, Massachusetts, USA) and expressed as mOsm kg-1 $\mathrm{H}_{2} \mathrm{O}$. Water chemistry data are shown in Supplementary File 1 .

\subsection{Cloning of tshb}

The sequence of the beta subunit of $t s h$ was originated using a cDNA cloned from a seabream pituitary cDNA library (Louro et al., 2005). Plasmid DNA was extracted using the alkaline lysis procedure (Birnboim and Doly, 1979) and sequenced using the Sanger sequencing method. Sequence identity was determined using the tblastx and blastn algorithms (Altschul et al., 1994) against the non-redundant nucleotide (nr db) and GenBank EST databases. Homologues were defined as those with an E-value $<1 \mathrm{e}^{-5}$ and a score of $>40$. Several cDNA clones corresponding to tshb were identified; one cDNA clone (281 EP10C7 Sa) was selected as reference and fully sequenced in order to obtain 3-fold coverage.

\subsection{Phylogenetic analyses}

Clustal Omega (SeaView v4 software, Gouy et al., 2010) with default parameters was used to generate a multiple sequence alignment of tshb sequences from representatives of the main vertebrate taxa.

Model Generator v0.85 (Keane et al., 2006) was used to test which substitution model best fitted the amino acid (aa) sequence alignment data. The Maximum Likelihood (ML) method, based on the selected optimal matrix-based model (JTT) (Jones et al., 1992), was used for the evolutionary analyses conducted in MEGA6 (Tamura et al., 2013). The bootstrap consensus tree was inferred from 1000 replicates (Felsenstein, 1985), and only branches corresponding to partitions reproduced in $>50 \%$ bootstrap replicates were presented. Initial tree(s) for the heuristic search were obtained automatically by applying Neighbor-Join and BioNJ algorithms to a matrix of pairwise distances estimated using a JTT model, and then selecting the topology with a superior log likelihood value. A discrete gamma distribution was used to model evolutionary rate differences among sites [ 5 categories $(+G$, parameter $=1.7029)]$. All positions containing gaps and missing data were eliminated. 


\subsection{Real-time quantitative PCR ( $q P C R$ )}

Total RNA was extracted from the pituitary, gills and kidney using Mini or Midi RNeasy kits (Qiagen, Hilden, Germany) following the manufacturer's protocol. The concentration of RNA was determined at $260 \mathrm{~nm}$ using BioPhotometer Plus Spectrophotometer (Eppendorf, Hamburg, Germany) and its quality was determined in a 2100 Bioanalyzer using the RNA 6000 Nano Kit (Agilent Technologies, Santa Clara, CA, USA). Only samples with an RNA Integrity Number (RIN) higher than 9.0 were used for qPCR. Synthesis of cDNA was carried out in a final reaction volume of $20 \mu \mathrm{L}$ using qSCRIPT ${ }^{\mathrm{TM}}$ CDNA synthesis kit (Quanta BioSciences, Gaithersburg, MD, USA). Primers used for the analysis were designed using Primer3 software (v. 0.4.0.) (http:// frodo.wi.mit.edu/primer3) and seabream cDNA sequences available in GenBank: deiodinase type 1 (dio1, DQ888894); deiodinase type 2 (dio2, DQ888895); tshb (KM014688); and $\beta$-actin ( $a c t b$, X89920). qPCR assay linearity and amplification efficiencies (Supplementary File 2) were checked using dilution curves (six serial 1/4 dilutions, in triplicate, starting from $10 \mathrm{ng}$ of cDNA, calculated from total input of RNA per reaction). All optimized qPCR assay were linear through 6 serial dilutions (dio1: $\mathrm{r}^{2}=0.982$, efficiency $(\mathrm{E})=0.90 ;$ dio2: $\mathrm{r}^{2}=0.982, \mathrm{E}=$ $0.90 ;$ tsh $\beta: \mathrm{r}^{2}=0.998, \mathrm{E}=0.90 ; \beta$-actin: $\mathrm{r}^{2}=0.999, \mathrm{E}=1.01$ ). To confirm the correct amplification of these primer pairs, the obtained PCR amplicons were cloned and sequenced (CloneJET PCR Cloning Kit, ThermoFisher Scientific, Waltham, MA, USA). qPCR was carried out with a Fluorescent Quantitative Detection System (Mastercycler ep realplex ${ }^{2}$ S, Eppendorf, Hamburg, Germany). Each reaction was carried out in triplicate and contained $10 \mathrm{ng}$ cDNA/total input of RNA, $0.5 \mu \mathrm{L}$ of each specific forward and reverse primer, and $5 \mu \mathrm{L}$ of PerfeCTa SYBR ${ }^{\circ}$ Green FastMix ${ }^{\mathrm{TM}}$ (Quanta BioSciences) in a final reaction volume of $10 \mu \mathrm{L}$. The thermal cycle utilized was $10 \mathrm{~min}$ at $95^{\circ} \mathrm{C} ; 40$ cycles of $20 \mathrm{~s}$ at $95^{\circ} \mathrm{C}$ followed by $30 \mathrm{~s}$ at $60^{\circ} \mathrm{C}$; melting curve $\left(60^{\circ} \mathrm{C}\right.$ to $\left.95^{\circ} \mathrm{C}, 20 \mathrm{~min}\right)$; $95^{\circ} \mathrm{C}, 15 \mathrm{~s}$. A final melt curve showed single product/dissociation curves in all reactions. The results for each gene were normalized to $a c t b$, which was stable between all samples analysed $\left(<0.35 \mathrm{C}_{\mathrm{T}}\right.$ variation). Relative gene quantification was performed using the $\Delta \Delta \mathrm{C}_{\mathrm{T}}$ method (Livak and Schmittgen, 2001).

\subsection{Outer ring deiodination (ORD) activities}

Tracers used for measurements of deiodinase activity were prepared using the chloramine-T method to produce $\left[{ }^{125} \mathrm{I}^{-}\right] \mathrm{rT} 3,\left[{ }^{125} \mathrm{I}^{-}\right] \mathrm{T} 3$ and $\left[{ }^{125} \mathrm{I}^{-}\right] \mathrm{T} 4$ from the 3,3'-T2, 3,5-T2 and 3,5,3'-T3, respectively (Visser et al., 1977). All those molecules have been reported as substrates for ORD activity in teleost fish (Klaren et al., 2012). Iodothyronines were purchased from Sigma Chemical Co. (St. Louis, MO, USA), Na ${ }^{125}$ I was obtained from NEN Life Science Products Inc., Boston, MA, USA. Radiolabelled iodothyronines from the radioiodination reaction were purified using 10\% ( $w / v)$ Sephadex LH-20 minicolumns as described previously (Mol and Visser, 1985) followed by high pressure liquid chromatography (HPLC, platinum column EPS C18, $150 \mathrm{~mm}$ length, internal diameter $4.6 \mathrm{~mm}$, Alltech Associated Inc., Illinois, USA) with a reverse phase isocratic elution of $35 / 65 \%$ acetonitrile $0.05 \mathrm{M} \mathrm{K}_{2} \mathrm{HPO}_{4}$, pH 3.2. Sephadex LH-20 was obtained from Amersham Pharmacia Biotech (Uppsala, Sweden). All other chemicals were analytical grade and obtained from commercial suppliers.

Gills and kidneys were homogenized in $1 \mathrm{~mL}$ and $3 \mathrm{~mL}$ of phosphate buffer (100 mM Na-phosphate, 2 mM EDTA, pH 7.2), respectively. To determine ORD activities, homogenates were incubated with $\left[{ }^{125} \mathrm{I}^{-}\right] \mathrm{rT3},\left[{ }^{125} \mathrm{I}^{-}\right] \mathrm{T} 3$ or $\left[{ }^{125} \mathrm{I}^{-}\right] \mathrm{T} 4$ without DTT as previously described (Klaren et al., 2005). Protein concentrations in the homogenates were measured with a Coomassie Brilliant Blue reagent kit (Bio-Rad, München, Germany) using bovine serum albumin (BSA) as the standard. Deiodination rates were normalized using the total homogenate protein in the reaction and were corrected for non-enzymatic deiodination.

\subsection{Plasma parameters}

Plasma osmolality was measured with a vapour pressure osmometer and expressed as mOsm kg ${ }^{-1} \mathrm{H}_{2} \mathrm{O}$. Plasma glucose, lactate and triglyceride levels were measured using commercial kits from Spinreact adapted to 96 -well microplates. The total plasma protein concentration was determined in diluted plasma samples using a bicinchoninic acid BCA Protein Assay Kit (Pierce, IL, USA) using BSA as a standard. All assays were performed with a Bio Kinetic EL-340i Automated Microplate Reader (BioTek Instruments, Winooski, VT, USA) using Deltasoft3 software for Macintosh (BioMetallics Inc., Princeton Junction, NJ, USA).

Plasma cortisol was measured by radioimmunoassay (RIA) (Arends et al., 1999). Plasma free thyroxine (fT4) concentrations were determined using a commercially available kit (DELFIA $®$ fT4, PerkinElmer Life and Analytical Sciences, Turku, Finland), which consists of a solid phase time-resolved fluoroimmunoassay reaction and measurements were performed using a Wallac Victor ${ }^{2} 1420$ multilabel counter. Serially diluted S. aurata charcoal-stripped plasma produced binding curves that were parallel to the standard curve (results not shown).

Plasma free triiodothyronine (fT3) levels were measured with a solid phase competitive ELISA (Human Diagnostics, Wiesbaden, Germany) according to the manufacturer's instructions as previously described for this species (Vargas-Chacoff et al., 2016). Absorbance was measured in a Bio-Rad Model-680 microplate reader (Bio-Rad, Veenendaal, The Netherlands). Samples were diluted with S. aurata charcoal-stripped plasma when the measured concentrations of fT3 were above the maximum standard concentration.

\subsection{0. $\mathrm{Na}^{+} / \mathrm{K}^{+}$-ATPase activity}

$\mathrm{Na}^{+} / \mathrm{K}^{+}$-ATPase activities in gill and kidney homogenates were determined in microplates using McCormick's method (McCormick, 1993) with modifications (Mancera et al., 2002).

\subsection{Statistics}

Differences between groups were tested using a one-way ANOVA with environmental salinity as the factor of variance. When necessary, data were logarithmically transformed to fulfil the requirements for parametric ANOVA. Normality was analysed using the Kolmogorov-Smirnov's test. The homogeneity of variances was analysed using Levene's test. When ANOVA yielded significant differences, Tukey's post-hoc test was used to identify significantly different groups. When data did not comply with the premises of the parametric ANOVA, data were analysed using a Kruskal-Wallis ANOVA by ranks. Correlations between free THs, relative to mRNA expression of $\operatorname{tsh} \beta$, dio 1 and dio2, and ORD activities in gill and kidney were analysed using linear regression on mean values of parameters measured in the experimental groups, as previously described (Speers-Roesch et al., 2015). Statistical significance was accepted at $p<0.05$. All the results are given as mean \pm standard error of the mean (SEM).

\section{Results}

\subsection{Biometrics}

None of the groups differed in length or body mass at the start of the 14-days acclimation period (data not shown). No mortality was recorded during the experimental period. At the end of the acclimation period HSI decreased significantly in animals exposed to 55 ppt (HSI $0.67 \pm$ $0.05 \%$ ) compared to animals acclimated to 15 ppt (HSI $0.94 \pm 0.06 \%$ ) or 40 ppt (HSI $0.96 \pm 0.06 \%$ ). 


\subsection{Tshb amino acid sequence}

The full-length sequence of $S$. aurata tshb consisted of 870 bp (accession number KM014688) and had an open reading frame (ORF) of 438 nucleotides that encoded a 146 aa protein (Supplementary File 3). Multiple sequence alignment of Tshb (Supplementary File 4) from seabream and a wide selection of vertebrates revealed they shared from $39 \%$ aa sequence conservation with mammals and reptiles (anole lizard) up to 92\% aa sequence conservation with Perciformes (European sea bass) (Supplementary File 5). In common with other jawed vertebrates $S$. aurata, Tshb possessed a signal peptide of 20 aa and contained 12 conserved cysteine residues and a putative site for asparagine-linked glycosylation (Supplementary File 5).

Evolutionary analysis of $S$. aurata Tshb using the maximum likelihood method confirmed its identity and revealed that the branching of the consensus phylogenetic tree was consistent with established evolutionary relationships (Fig. 1). The exception was the chondrosteian Siberian sturgeon that grouped with the tetrapods. Percomorphs grouped into one clade, with tetraodontidae (82-84\% aa sequence conservation), cichlids ( $84 \%$ aa sequence conservation) and ovalentaria (medaka and platy fish, $71-78 \%$ aa sequence conservation) in subclades. The Perciformes grouped into a consistent clade with the exception of the ovalentaria, a newly established fish clade (Wainwright et al., 2012). Seabream Tshb shared 70\% aa sequence identity with Salmoniformes and 60\% with Cypriniformes. The aa sequence identity between seabream Tshb and tetrapod TSHB was approximately $40 \%$.

\subsection{Pituitary tshb mRNA expression}

Pituitary tshb gene expression was significantly $(p<0.05)$ higher $(65 \%)$ in animals acclimated to 55 ppt salinity compared to groups acclimated to 5 or 40 ppt salinity (Fig. 2). No significant differences were detected between animals acclimated to $15 \mathrm{ppt}$ and any of the other groups.

\subsection{Plasma fTH levels}

Free T4 (fT4) concentrations in plasma were significantly higher ( $p=0.0002$, one-way ANOVA followed by a Tukey post hoc test; salinity effect $p=0.014 ; N=4$ per group) in animals acclimated to 5 and 15 ppt compared to fish acclimated to 40 and 55 ppt salinities. Plasma free T3 was also significantly higher ( $p$ between 0.019 and 0.010 , one-way ANOVA followed by a Tukey post hoc test; salinity effect

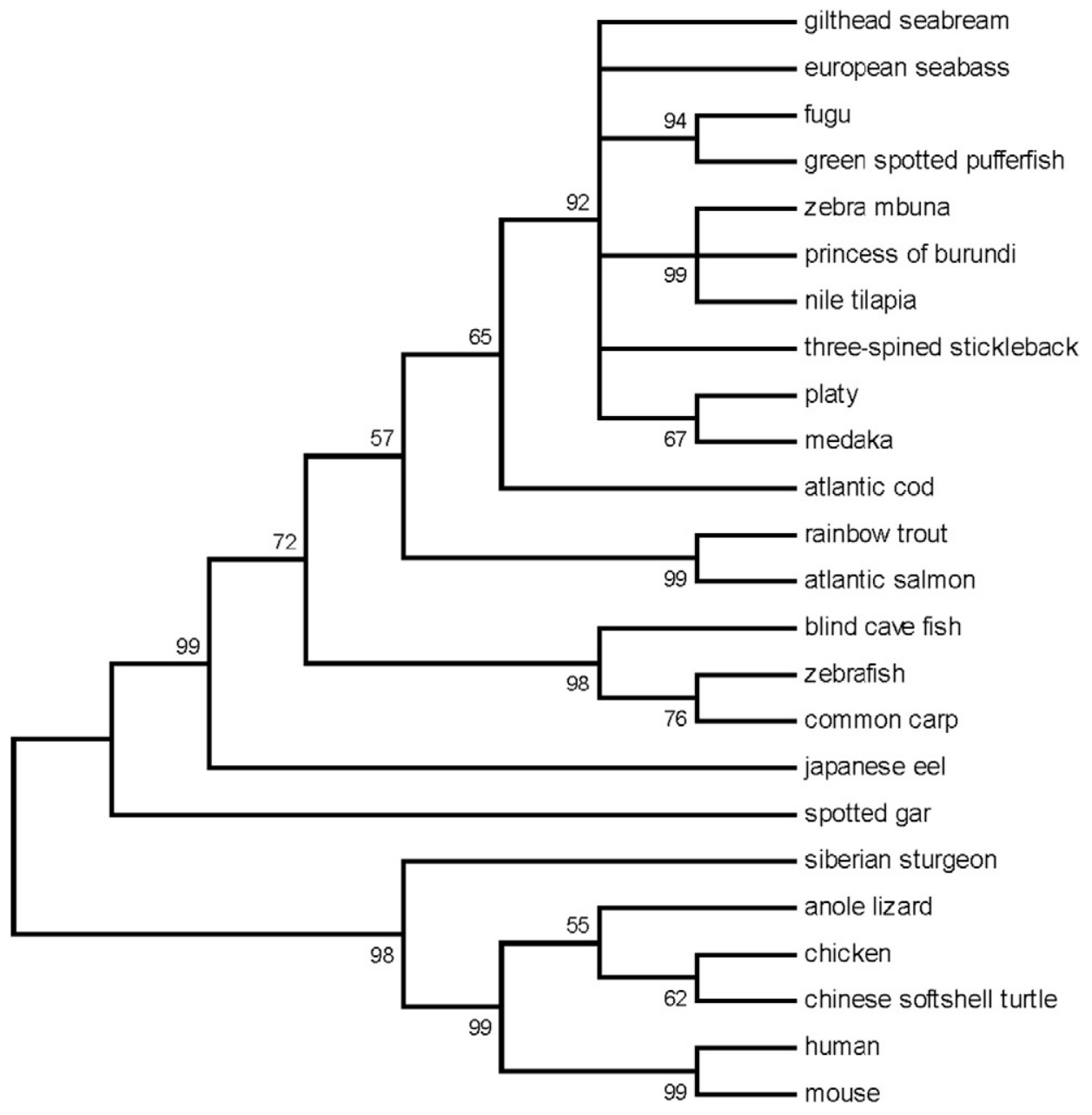

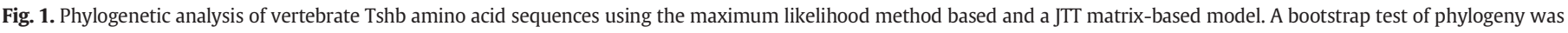

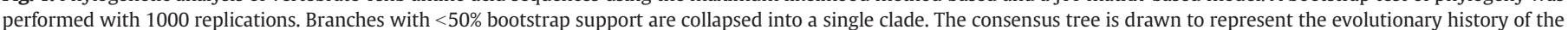

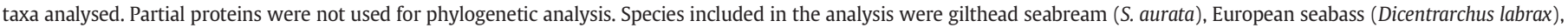

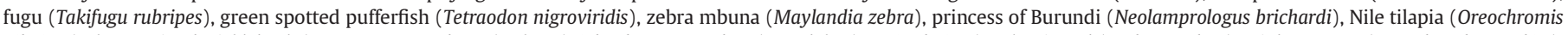

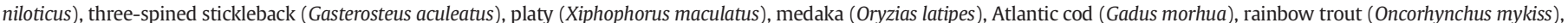

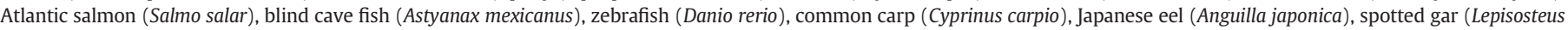

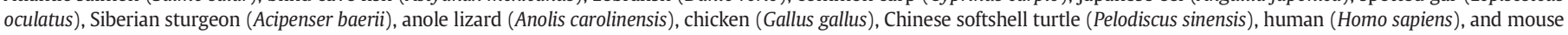
(Mus musculus). 


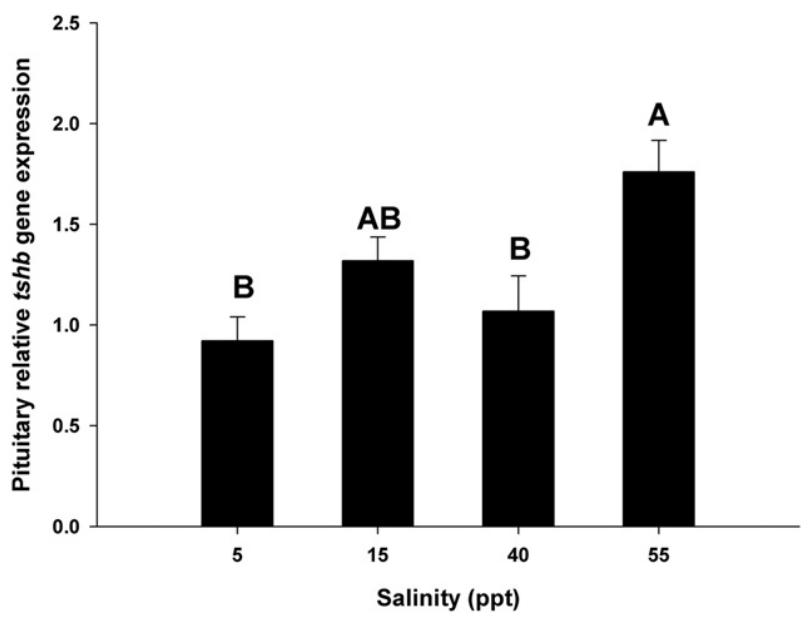

Fig. 2. Expression of tshb in pituitary of seabream. Quantitative real-time PCR analysis of tsh $b$ transcript abundance in the pituitary gland of seabream after acclimation to 5,15 , 40 and 55 ppt salinity for two weeks. Data were normalized by dividing transcript number by the absolute value of $\beta$-actin in every sample. Results are expressed as mean \pm SEM $(N=8)$. Different letters indicate significant differences among groups (one-way ANOVA followed by a Tukey test, $p<0.05$ ).

$p=0.0019 ; \mathrm{N}=4$ per group) in fish acclimated to 5 ppt compared to those maintained at 15, 40 and 55 ppt (Fig. 3).

\subsection{Deiodinases type 1 and 2 mRNA expression in gills and kidney}

Branchial dio1 transcript abundance was significantly lower in seabream acclimated to 5 ppt salinity, with $37 \%$ lower mRNA expression in the 5 ppt-acclimated fish relative to those maintained at $40 \mathrm{ppt}$ (control) and 55 ppt salinity (salinity effect $p=0.025 ; N=5$ per group). Conversely, deiodinase type 2 (dio2) gene expression was significantly higher (salinity effect $p=0.007 ; \mathrm{N}=5$ per group) in fish acclimated to 15 ppt compared to fish at 40 and 55 ppt salinity (Fig. 4A). In contrast, transcript abundance of deiodinase type 1 (dio1) in kidney did not vary between groups. However, dio2 expression was significantly higher in the 5 ppt group (210\% higher than the control group) compared to the 55 ppt salinity group (25\% less expression than the control group (Fig. 4B).

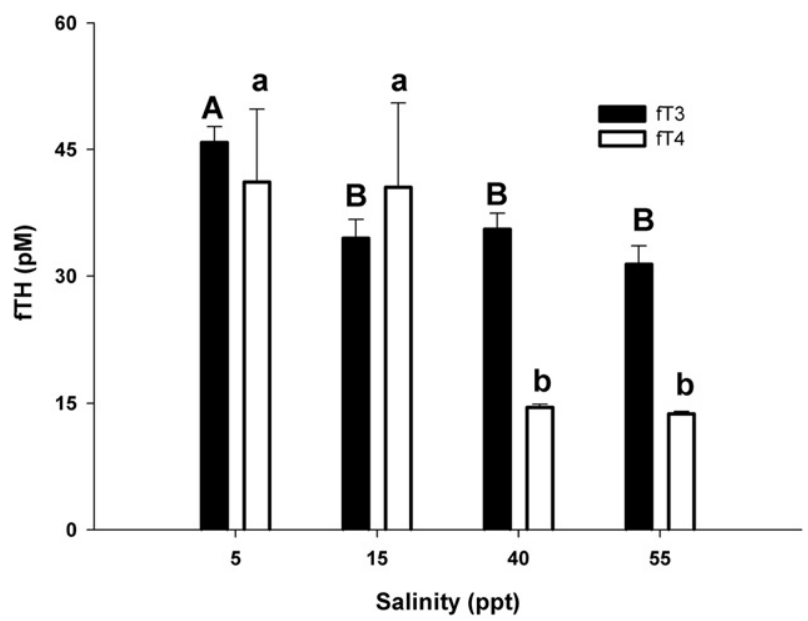

Fig. 3. Plasma concentrations for free thyroid hormones (fT3 and fT4) in seabreams acclimated to four different environmental salinities for two weeks (black bars, fT3; white bars, fT4). Results are expressed as mean \pm SEM $(N=4)$. Different letters indicate significant differences among groups (capital and lowercase letters represent fT3 and fT4, respectively). Further details as in legend of Fig. 2.
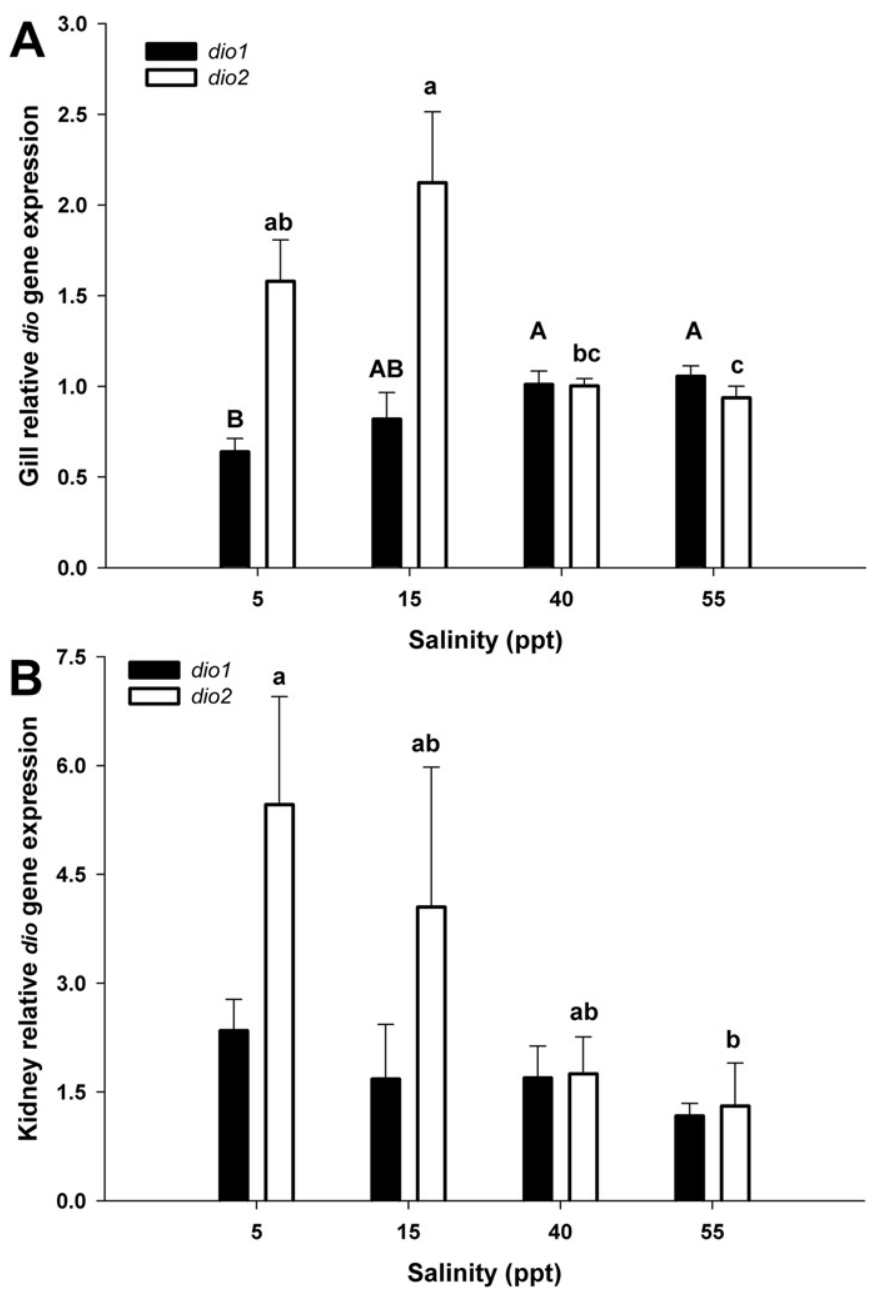

Fig. 4. Expression of dio1 and dio2 in osmoregulatory tissues of seabream. Branchial (A) and renal (B) quantitative real-time PCR analysis of deiodinases 1 and 2 (dio1, black bars; and dio2, white bars) relative transcript abundance in seabream individuals acclimated to four different environmental salinities for two weeks. Different letters indicate significant differences among groups (capital and lowercase letters represent dio1 and dio2 mRNA expression, respectively). Further details as in legend of Fig. 2.

\subsection{ORD activity in gills and kidney}

Branchial and renal T4-ORD activities were higher in animals acclimated to salinities of 5 and 15 ppt compared to animals acclimated to 40 and 55 ppt salinity (Fig. 5). However, when incubated with rT3, gill and renal ORD activities were not significantly different between groups. Kidney T3-ORD activity increased with increased salinity with T3-ORD rates measured at 40 and 55 ppt twice as high as those measured at 5 ppt.

\subsection{Plasma osmolality, metabolites and cortisol levels}

Plasma parameters significantly differed between the experimental groups (Table 1). Plasma osmolality increased with increasing salinity. In general, all plasma metabolite concentrations were significantly higher in fish at $55 \mathrm{ppt}$ and lower in fish at 5 ppt compared with fish at 15 ppt and 40 ppt salinities. Plasma cortisol concentrations were similar between all the experimental groups.

\subsection{Correlations between components of the thyroid system}

Correlations between elements of the thyroid system in fish exposed to different salinities are indicated in Supplementary File 6. Correlation 


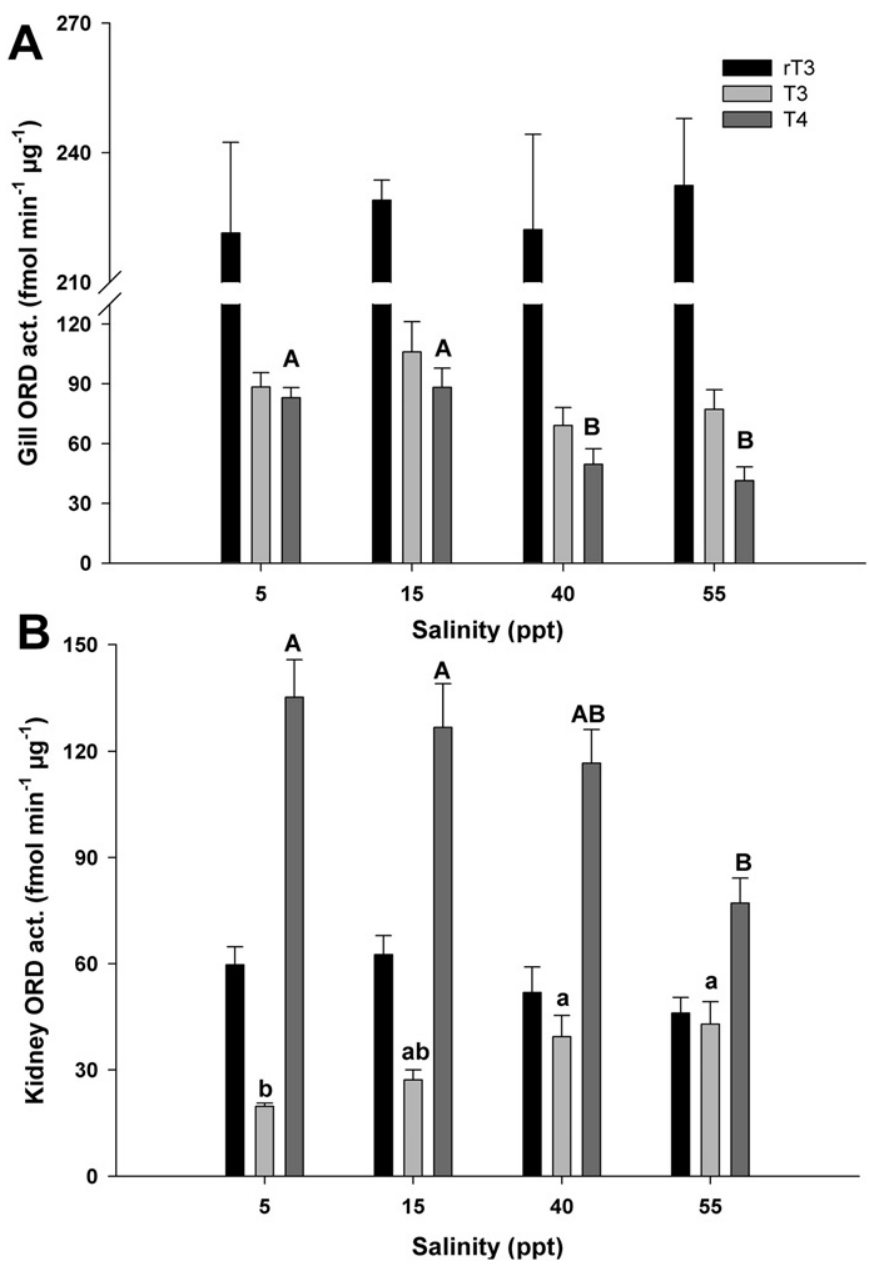

Fig. 5. Outer ring deiodination activity in osmoregulatory tissues of seabream. Branchial (A) and renal (B) outer ring deiodination (ORD) activities when incubating with reverse T3 (black bars), 3,5,5'-T3 (light grey bars) and T4 (dark grey bars) in seabream animals acclimated to four different environmental salinities for two weeks. Results are expressed as mean \pm SEM $(N=5)$. Different letters indicate significant differences among groups (capital and lowercase letters represent T4- and T3-ORD activity, respectively). Further details as in legend of Fig. 2.

analysis revealed the highest plasma fT3 levels inhibited pituitary tshb mRNA expression (Pearson $r$ coefficient, $r=-0.820$ ). Hence, $67.2 \%$ of the variance of $t$ shb expression was explained by plasma fT3 concentrations $\left(r^{2}=0.672, p=0.180\right)$. A positive correlation was found between plasma fT4 and higher dio2 expression in gills and kidney $\left(\mathrm{r}^{2}=0.827\right.$ and $r^{2}=0.917$, respectively). Branchial dio2 expression correlated positively with T3- and T4-ORD branchial activities $\left(\mathrm{r}^{2}=0.933\right.$ and $\mathrm{r}^{2}=$ 0.894 , respectively). In this sense, renal dio2 expression correlated positively with rT3- and T4-ORD renal activities $\left(r^{2}=0.764\right.$ and $r^{2}=0.684$, respectively), but was negatively correlated with T3-ORD activity in this

Table 1

Plasmatic metabolites and osmoregulatory parameters in seabream individuals acclimated to four different environmental salinities for two weeks. Results are expressed as mean \pm SEM $(\mathrm{N}=8)$. Different letters indicate significant differences among groups (one-way ANOVA followed by a Tukey test, $\mathrm{p}<0.05$ ).

\begin{tabular}{lllll}
\hline Parameter & $5 \mathrm{ppt}$ & $15 \mathrm{ppt}$ & $40 \mathrm{ppt}$ & $55 \mathrm{ppt}$ \\
\hline Glucose $(\mathrm{mM})$ & $3.4 \pm 0.3^{\mathrm{b}}$ & $4.3 \pm 0.3^{\mathrm{ab}}$ & $3.3 \pm 0.2^{\mathrm{b}}$ & $4.5 \pm 0.2^{\mathrm{a}}$ \\
Lactate $(\mathrm{mM})$ & $1.7 \pm 0.1^{\mathrm{b}}$ & $2.7 \pm 0.3^{\mathrm{a}}$ & $2.2 \pm 0.2^{\mathrm{ab}}$ & $3.5 \pm 0.1^{\mathrm{a}}$ \\
TAG $(\mathrm{mM})$ & $1.1 \pm 0.1^{\mathrm{b}}$ & $1.8 \pm 0.1^{\mathrm{a}}$ & $1.8 \pm 0.1^{\mathrm{a}}$ & $1.5 \pm 0.1^{\mathrm{ab}}$ \\
Proteins $\left(\mathrm{g} \mathrm{L}^{-1}\right)$ & $37.8 \pm 1.2^{\mathrm{b}}$ & $37.1 \pm 1.4^{\mathrm{b}}$ & $38.6 \pm 0.7^{\mathrm{b}}$ & $44.5 \pm 1.8^{\mathrm{a}}$ \\
Osmolality $\left(\mathrm{mOsm} \mathrm{kg}^{-1}\right)$ & $358 \pm 2^{\mathrm{c}}$ & $384 \pm 5^{\mathrm{b}}$ & $381 \pm 5^{\mathrm{b}}$ & $444 \pm 9^{\mathrm{a}}$ \\
Cortisol $\left(\mathrm{ng} \mathrm{mL}^{-1}\right)$ & $19.4 \pm 4.7$ & $18.8 \pm 5.2$ & $20.8 \pm 5.7$ & $7.2 \pm 1.6$ \\
\hline
\end{tabular}

tissue $\left(r^{2}=0.998\right)$. Finally, plasma fT3 displayed a positive and strong correlation with renal dio1 expression $\left(r^{2}=0.935\right)$.

\section{9. $\mathrm{Na}^{+} / \mathrm{K}^{+}$-ATPase activity in gills and kidney}

Branchial $\mathrm{Na}^{+} / \mathrm{K}^{+}$-ATPase activity as a function of ambient salinity was significantly higher in fish acclimated to 55 and 5 ppt salinities compared to fish at 15 ppt salinity. Renal $\mathrm{Na}^{+} / \mathrm{K}^{+}$-ATPase activity was not significantly different between experimental fish groups (Supplementary File 7).

\section{Discussion}

The present study substantiates the notion that the thyroid system is regulated by changes in salinity in gilthead seabream. In this sense, a range covering 5 to 55 ppt salinity modified tsh $b$ gene expression, fTHs concentrations in plasma, ORD activities and relative mRNA levels of deiodinases in osmoregulatory organs (gills and kidney). The change in the thyroid system in response to a salinity challenge suggests it is involved and/or affected during the acclimation of seabream to changing osmolality conditions. Physiological processes regulated by the thyroid system such as growth or reproduction (Nugegoda and Kibria, 2016), of paramount relevance for the aquaculture, will consequently be modified when seabream culture occurs at different salinities.

Although pituitary tshb is differentially expressed in response to environmental salinity, only $67.2 \%$ of its variance is explained by changes in plasma fT3, and less by plasma fT4 (23.6\%) (Supplementary File 6). Our findings reveal that although fT3 levels partially modulate pituitary expression of $t s h b$, its fine regulation is dependent on the total amount of T3 and/or T4 in plasma. Thus, the classical feedback mechanism in which plasma T3 regulates TSH secretion was evident only in the extreme-salinity groups ( 5 and $55 \mathrm{ppt}$ ). On the other hand, the absence of a clear correlation between plasma fTHs and pituitary expression of tshb may suggest that the thyroid system is not fully controlled by the pituitary, but may be fine-tuned at the peripheral tissue level.

Our findings indicate that gilthead seabream maintains thyroidal homeostasis (viz. stable fT3 concentrations in plasma) in a wide range of environmental salinities (from 15 to $55 \mathrm{ppt}$ ) by changing plasma fT4 levels (higher levels at hypo- and isosmotic environments), in common with what occurs in Solea senegalensis (Arjona et al., 2008) and Acipenser stellatus (Krayushkina et al., 2015). The differences in plasma fT4 levels in our study are probably due to changes in T4 production/secretion by the thyroid gland, and/or changes in peripheral thyroid hormone metabolism.

Deiodination of T4 towards the formation of the active T3 is carried out by Dio1 and Dio2 enzymes (Klaren et al., 2008). The substrate specificity of gilthead seabream Dio1 and Dio2 is not well established. In the present study, incubations with different substrates for the Dio1 and Dio2 deiodinases (T3, rT3 and T4), reveal that T4-ORD activity in gills and kidney decreases with environmental salinity while no changes in rT3-ORD activity occurred in any of the groups tested. Despite these similarities, there are some differences between both tissues that should be mentioned. In this sense, gill ORD activity is maximal when rT3 is the substrate (Fig. 5A), while the highest renal activity occurs with $\mathrm{T} 4$ as the substrate (Fig. 5B). These differences in deiodinase activity between the gills and the kidney may be explained by differing ratios of Dio1 and Dio2 enzymes in these tissues. Thus, the apparent substrate preference of mammalian and fish Dio1 for rT3 rather than T4 (Klaren et al., 2005; Kohrle, 1999) could indicate that the main deiodinase in gilthead seabream gills is Dio1. Herein, the expression of dio2 in both tissues positively correlates with T4-ORD activity (Supplementary File 6), pointing to T4 as the preferential substrate for gilthead seabream Dio2. Thus, the high T4-ORD activity revealed for the seabream kidney in the present study may indicate that the predominant deiodinase in this tissue is Dio2 rather than Dio1, even though Dio1 is also expressed. 
The presence of Dio2 in gills seems to depend on the fish species studied (Lorgen et al., 2015; Orozco et al., 2000), although recent studies in $S$. aurata have illustrated that the thyroid metabolism canonical pathway is clearly regulated by salinity changes in this osmoregulatory tissue (Martos-Sitcha et al., 2016). In S. aurata dio2 mRNA expression occurs not only in gills, but also in kidney indicating that Dio2 is relevant in osmoregulatory organs. We provide some correlations between plasma fT4 concentrations and expression of dio2 in both gills and kidney, indicating an enhancement in peripheral ORD activity when circulating T4 levels increase. The results of the present study in seabream coincide with those of previous studies in fish, as the expression of Dio2 is described to increase in hyposmotic salinities (López-Bojórquez et al., 2007) due to the presence of osmotic response elements in the dio2 promoter region (Lorgen et al., 2015). Moreover, gill dio1 expression increases with environmental salinity in S. aurata (Fig. 4A), and this may suggest that $\mathrm{TH}$ inactivation pathways (as this enzyme also presents inner ring deiodinase activity) are involved in acclimation to hyperosmotic conditions. The results obtained ex vivo when T3 was used as the substrate for kidney were negatively correlated with renal dio2 expression (Supplementary File 6), and this may indicate that high levels of T3 inhibit dio2 expression in this tissue. ORD and IRD (inner ring deiodination) processes could then be modulated jointly, as renal dio1 expression was upregulated by plasma fT3 concentrations (Supplementary File 6), sustaining an increased IRD activity in the kidney when T3 levels were high. However, the enhanced T3-ORD activity in kidney at higher salinities (40 and 55 ppt) was not accompanied by differences in dio1 transcript abundance suggesting that regulation of deiodinase transcription and translation diverge. Overall, our results of ORD activity and mRNA expression support the idea of Dio2 as the main "osmoregulatory deiodinase" in seabream with Dio1 taking a secondary role.

The elevated fTH levels measured in hyposmotic conditions (5 ppt) can be interpreted as an acclimation response that may increase the activity of ion transporters in osmoregulatory organs (Laiz-Carrion et al., 2005a). In this sense it was postulated that THs interact with other hormones such as cortisol and GH/IGF-I in order to increase the osmoregulatory capacity of fish (McCormick, 2011). As the highest fT3 levels shown in this study (fish acclimated to $5 \mathrm{ppt}$ ) are related to reduced growth rates (Laiz-Carrion et al., 2005b), it could be suggested that T3 reallocates metabolic energy from growth processes to ion transport and osmoregulation so that seabream can cope with the ionoregulatory demands dictated by low salinity ( $5 \mathrm{ppt}$ ) environments (higher ion transport and water retention). In agreement with this, gill $\mathrm{Na}^{+} / \mathrm{K}^{+}$-ATPase activity was maximal at $5 \mathrm{ppt}$. The metabolic actions of THs have been associated with increased plasma levels of energy metabolites (Vargas-Chacoff et al., 2016). However, the results of the present study are not in total concordance with this idea as seabream acclimated to 55 ppt had low levels of fTHs but a high concentration of metabolites in plasma and highest branchial NKA activity. Regarding to this, previous works reported in this species that extreme salinities are associated with higher gill NKA (Laiz-Carrion et al., 2005a) and thus metabolic activities. This may suggest that metabolite turnover is not only regulated by the thyroid system at this salinity ( $55 \mathrm{ppt})$.

In conclusion, the thyroid system of gilthead seabream (Sparus aurata) is regulated by salinity. Hypo- and isosmotic environments cause an increase in plasma fTH levels evoking a hyperthyroid condition. Environmental salinity modulated ORD activity in osmoregulatory tissues such as the gills and kidney supporting the idea that the thyroid system is involved in osmoregulation in fish. Gills seem to have predominantly Dio1 activity as indicated by high rT3-ORD activity, while kidney has mainly Dio2 activity, as indicated by the high T4-ORD activity. Dio2 seems to be more responsive to osmoregulatory changes than Dio1, and we propose Dio2 should be considered as the main "osmoregulatory deiodinase" in the seabream. Our results indicate that the peripheral tissue plays an important role in $\mathrm{TH}$ regulation during osmoregulation in seabream.
Supplementary data to this article can be found online at http://dx. doi.org/10.1016/j.cbpa.2016.08.013.

\section{Acknowledgments}

This work was partially supported by a Socrates/Erasmus Grant from the European Union and a Ph.D. scholarship from the University of Cadiz (UCA 2009-074-FPI) to I. R-J. It has been also supported by grants AGL2007-61211/ACU (Ministerio de Educación y Ciencia and FEDER, Spain) and Proyecto de Excelencia PO7-RNM-02843 (Junta de Andalucía) to J.M.M. BL (SFRH/BPD/89889/2012) and PISP (SFRH/BPD/84033/2012) were supported by the Science Foundation (FCT) of Portugal.

\section{References}

Altschul, S.F., Boguski, M.S., Gish, W., Wootton, J.C., 1994. Issues in searching molecular sequence databases. Nat. Genet. 6, 119-129.

Arends, R.J., Mancera, J.M., Munoz, J.L., Wendelaar Bonga, S.E., Flik, G., 1999. The stress response of the gilthead sea bream (Sparus aurata L.) to air exposure and confinement. J. Endocrinol. 163, 149-157.

Arjona, F.J., Vargas-Chacoff, L., Martin del Rio, M.P., Flik, G., Mancera, J.M., Klaren, P.H.M. 2008. The involvement of thyroid hormones and cortisol in the osmotic acclimation of Solea senegalensis. Gen. Comp. Endocrinol. 155, 796-803.

Bernier, N.J., Flik, G., Klaren, P.H.M., 2009. Regulation and Contribution of the Corticotropic, Melanotropic and Thyrotropic Axes to the Stress Response in Fishes. In: van der Kraak, G., Farrell, A.P., Brauner, C.J. (Eds.), N.J. Bernier. Fish Physiology. Academic Press, pp. 235-311.

Birnboim, H.C., Doly, J., 1979. A rapid alkaline extraction procedure for screening recombinant plasmid DNA. Nucleic Acids Res. 7, 1513-1523.

Blanton, M.L., Specker, J.L., 2007. The hypothalamic-pituitary-thyroid (HPT) axis in fish and its role in fish development and reproduction. Crit. Rev. Toxicol. 37, 97-115.

Cohn, W.B., Jones, R.A., Valverde, R.A., Leiner, K.A., MacKenzie, D.S., 2010. Molecular cloning and regulation of mRNA expression of the thyrotropin beta and glycoprotein hormone alpha subunits in red drum, Sciaenops ocellatus. Fish Physiol. Biochem. 36 1277-1290.

Eales, J.G., Brown, S.B., 1993. Measurement and regulation of thyroidal status in teleost fish. Rev. Fish Biol. Fish. 3, 299-347.

Felsenstein, J., 1985. Confidence limits on phylogenies: an approach using the bootstrap. Evolution 39, 783-791.

Garcia-G, C., Jeziorski, M.C., Valverde-R, C., Orozco, A., 2004. Effects of iodothyronines on the hepatic outer-ring deiodinating pathway in killifish. Gen. Comp. Endocrinol. 135, 201-209.

Gouy, M., Guindon, S., Gascuel, O., 2010. SeaView Version 4: a multiplatform graphical user interface for sequence alignment and phylogenetic tree building. Mol. Biol. Evol. 27, 221-224

Jones, D.T., Taylor, W.R., Thornton, J.M., 1992. The rapid generation of mutation data matrices from protein sequences. Comput. Appl. Biosci. 8, 275-282.

Keane, T., Creevey, C., Pentony, M., Naughton, T., Mclnerney, J., 2006. Assessment of methods for amino acid matrix selection and their use on empirical data shows that ad hoc assumptions for choice of matrix are not justified. BMC Evol. Biol. 6, 29.

Klaren, P.H.M., Haasdijk, R., Metz, J.R. Nitsch, L.M.C., Darras, V.M., Van der Geyten, S., Flik, G., 2005. Characterization of an iodothyronine 5'-deiodinase in gilthead seabream (Sparus auratus) that is inhibited by dithiothreitol. Endocrinology 146, 5621-5630.

Klaren, P.H.M., Guzman, J.M., Reutelingsperger, S.J., Mancera, J.M., Flik, G., 2007. Low salinity acclimation and thyroid hormone metabolizing enzymes in gilthead seabream (Sparus auratus). Gen. Comp. Endocrinol. 152, 215-222.

Klaren, P.H.M., Geven, E.J.W., Flik, G., 2008. The Involvement of the Thyroid Gland in Teleost Osmoregulation. In: Baldisserotto, B., Mancera, J.M., Kapoor, B.G. (Eds.), Fish Osmoregulation. Science Publisher, Enfield, USA, pp. 35-65.

Klaren, P.H.M., Geven, E.J.W., Nagelkerke, A., Flik, G., 2012. Kinetics and thiol requirements of iodothyronine 5'-deiodination are tissue-specific in common carp (Cyprinus carpio L.). Comp. Biochem. Physiol. B Biochem. Mol. Biol. 161, 275-282.

Kohrle, J., 1999. Local activation and inactivation of thyroid hormones: the deiodinase family. Mol. Cell. Endocrinol. 151, 103-119.

Krayushkina, L.S., Semenova, O.G., Vyushina, A.V., Gerasimov, A.A., 2015. Morphofunctional remodelling of the osmoregulatory system in starred sturgeon Acipenser stellatus (Acipenseridae) during transition from hyperosmotic to hypoosmotic regulation. J. Ichthyol. 55, 259-272.

Laiz-Carrion, R., Guerreiro, P.M., Fuentes, J., Canario, A.V.M., Martin Del Rio, M.P., Mancera, J.M., 2005a. Branchial osmoregulatory response to salinity in the gilthead sea bream, Sparus auratus. J. Exp. Zool. A 303A, 563-576.

Laiz-Carrion, R., Sangiao-Alvarellos, S., Guzman, J.M., Martin del Rio, M.P., Soengas, J.L., Mancera, J.M., 2005b. Growth performance of gilthead sea bream Sparus aurata in different osmotic conditions: implications for osmoregulation and energy metabolism. Aquaculture 250, 849-861.

Leatherland, J.F., Farbridge, K.J., 1992. Chronic fasting reduced the response of the thyroid to growth hormone and TSH, and alers the growth hormone-related changes in hepatic 5'-monodeiodinase activity in rainbow trout, Oncorhynchus mykiss. Gen. Comp. Endocrinol. 87, 342-353. 
Livak, K.J., Schmittgen, T.D., 2001. Analysis of relative gene expression data using realtime quantitative PCR and the 2- $\triangle \Delta C T$ method. Methods 25, 402-408.

López-Bojórquez, L., Villalobos, P., Garcia-G, C., Orozco, A., Valverde-R, C., 2007. Functional identification of an osmotic response element (ORE) in the promoter region of the killifish deiodinase 2 gene (FhDio2). J. Exp. Biol. 210, 3126-3132.

Lorgen, M., Casadei, E., Krol, E., Douglas, A., Birnie, M.J., Ebbesson, L.O., Nilsen, T.O., Jordan, W.C., Jorgensen, E.H., Dardente, H., Hazlerigg, D.G., Martin, S.A., 2015. Functional divergence of type 2 deiodinase paralogs in the Atlantic salmon. Curr. Biol. 25, 936-941.

Louro, B., Passos, A.L., Power, D., 2005. Transcriptome analysis of the gilthead sea bream (Sparus auratus) pituitary gland: type I markers for molecular genetics. Rev. Port. Zootec. 12, 91-105.

Mancera, J.M., Laiz Carrion, R., Martín del Río, M.P., 2002. Osmoregulatory action of PRL $\mathrm{GH}$, and cortisol in the gilthead seabream (Sparus aurata L.). Gen. Comp. Endocrinol. 129, 95-103.

Manchado, M., Infante, C., Asensio, E., Planas, J.V., Canavate, J.P., 2008. Thyroid hormones down-regulate thyrotropin [beta] subunit and thyroglobulin during metamorphosis in the flatfish Senegalese sole (Solea senegalensis Kaup). Gen. Comp. Endocrinol. 155, 447-455.

Martos-Sitcha, J.A., Mancera, J.M., Calduch-Giner, J.A., Yufera, M., Martinez-Rodriguez, G., Perez-Sanchez, J., 2016. Unraveling the tissue-specific gene signatures of gilthead sea bream (Sparus aurata L.) after hyper- and hypo-osmotic challenges. PLoS One 11, e0148113.

McCormick, S.D., 1993. Methods for nonlethal gill biopsy and measurement of $\mathrm{Na}+$ $\mathrm{K}+$-ATPase activity. Can. J. Fish. Aquat. Sci. 50, 656-658.

McCormick, S.D., 2011. The hormonal control of osmoregulation in teleost fish. In: Farrell, A.P. (Ed.), Encyclopedia of Fish Physiology: From Genome to Environment. Academic Press, San Diego, pp. 1466-1473.

Mol, J.A., Visser, T.J., 1985. Rapid and selective inner ring deiodination of thyroxine sulfate by rat liver deiodinase. Endocrinology 117, 8-12
Nugegoda, D., Kibria, G., 2016. Effects of environmental chemicals on fish thyroid function: implications for fisheries and aquaculture in Australia. Gen. Comp. Endocrinol. http://dx.doi.org/10.1016/j.ygcen.2016.02.021.

Orozco, A., Silva, J.E., Valverde, R.C., 1997. Rainbow trout liver expresses two iodothyronine phenolic ring deiodinase pathways with the characteristics of mammalian types I and II 5'-deiodinases. Endocrinology 138, 254-258.

Orozco, A., Linser, P., Valverde, C., 2000. Kinetic characterization of outer-ring deiodinase activity (ORD) in the liver, gill and retina of the killifish Fundulus heteroclitus. Comp. Biochem. Physiol. B Biochem. Mol. Biol. 126, 283-290.

Power, D.M., Llewellyn, L., Faustino, M., Nowell, M.A., Björnsson, B.T., Einarsdottir, I.E., Canario, A.V.M., Sweeney, G.E., 2001. Thyroid hormones in growth and development of fish. Comp. Biochem. Physiol. C 130, 447-459.

Speers-Roesch, B., Robinson, J.L., Val, A.L., Almeida-Val, V.M.F., Driedzic, W.R., 2015. Interspecific dietary diversity has little influence on pathways of glucose metabolism in liver and heart of piranhas and pacus (family Serrasalmidae). Hydrobiologia 1-15 http://dx.doi.org/10.1007/s10750-015-2562-0.

Tamura, K., Stecher, G., Peterson, D., Filipski, A., Kumar, S., 2013. MEGA6: Molecular Evolutionary Genetics Analysis version 6.0. Mol. Biol. Evol. 30, 2725-2729.

Vargas-Chacoff, L., Ruiz-Jarabo, I., Arjona, F.J., Laiz-Carrion, R., Flik, G., Klaren, P.H.M., Mancera, J.M., 2016. Energy metabolism of hyperthyroid gilthead sea bream Sparus aurata L. Comp. Biochem. Physiol. A Mol. Integr. Physiol. 191, 25-34.

Visser, G.J., Docter, R., Hennemann, G., 1977. Radioimmunoassay of reverse tri-iodothyronine. J. Endocrinol. 73, 395-396.

Wainwright, P.C., Smith, W.L., Price, S.A., Tang, K.L., Sparks, J.S., Ferry, L.A., Kuhn, K.L., Eytan, R.I., Near, T.J., 2012. The evolution of pharyngognathy: a phylogenetic and functional appraisal of the pharyngeal jaw key innovation in labroid fishes and beyond. Syst. Biol. 61, 1001-1027. 